\title{
PERBANDINGAN NILAI MORAL NOVEL ANANTA PRAHADI DAN IVANNA VAN DIJK KARYA RISA SARASWATI
}

\author{
Inda Puspita Sari ${ }^{1}$, Tiya Handayani ${ }^{2}$, Rika Berlista ${ }^{3}$ \\ STKIP-PGRI Lubuklinggau ${ }^{1,2,3}$ \\ indashop21@gmail.com ${ }^{1}$
}

Submit, 28-09-2019 Accepted, 27-12-2019 Publish, 27-12-2019

\begin{abstract}
ABSTRAK
Penelitian ini bertujuan untuk mendeskripsikan perbandingan nilai moral dalam novel Ivanna Van Dijk karya Risa Saraswati dengan nilai moral novel Ananta Prahadi karya Risa Saraswati. Metode penelitian menggunakan metode deskriftif kalitatif. Data dalam penelitian ini diperoleh dengan teknik membaca, mencatat, dan menyimpulkan. Setelah data terkumpul, kemudian dilakukan reduksi data. Data yang telah dipilih kemudian diklasifikasikan untuk selanjutnya dianalisis persamaan dan perbedaannya untuk dibandingkan hingga kemudian dilakukan penyimpulan hasil penelitian. Hasil penelitian ini menunjukkan bahwa adanya perbedaan dan persamaan nilai moral hubungan manusia dengan diri sendiri, hubungan manusia dengan manusia, dan hubungan manusia dengan Tuhan.Perbandingan nilai moral kedua novel tersebut dari aspek nilai moral terdapat perbedaan. Pada novel Ananta Prahadi karya Risa Saraswati nilai moral hubungan manusia dengan diri sendiri terdapat 19 kutipan, hubungan manusia dengan manusia terdapat 50 kutipan, hubungan manusia dengan Tuhan terdapat 8 , dan keseluruhan dari kutipan tersebut adalah 149 kutipan. Sedangkan pada novel Ivanna Van Dijk nilai moral hubungan manusia dengan diri sendiri terdapat 26 kutipn, hubungan manusia dengan manusia terdapat 49 kutipan, hubungan manusia dengan Tuhan terdapat 3 kutipan, dan keseluruhan dari kutipan tersebut adalah 105 kutipan.Simpulan, perbandingan nilai moral pada ke dua novel adalah pada jumlah kutipan, sedangkan persamaannya terletak pada bentuk kutipan nilai moral, yang mendominasi yaitu nilai moral hubungan dengan sesama. Selain itu bentuk penyapaian nilai moral dari ke dua novel sedikit berbeda, yaitu pada makna tersirat dan tersuratnya.
\end{abstract}

Kata Kunci : Perbandingan, Novel, Nilai Moral

\section{ABSTRACT}

This study aims to describe the comparison of moral values in the novel Ivanna Van Dijk by RisaSaraswati with the moral values of the novel AnantaPrahadi by RisaSaraswati. The research method uses descriptive qualitative method. The data in this study were obtained by reading, recording and concluding techniques. After the data is collected, data reduction is then performed. The selected data are then classified for further analysis of similarities and differences to be compared until the conclusion of the research results. The results of this study indicate that there are differences and similarities in the moral values of human relations with oneself, human relations with humans, and human relations with God. Comparison of the moral values of the two 
novels from the aspect of moral values there are differences. In the novel AnantaPrahadi by RisaSaraswati the moral values of human relations with oneself are 19 quotations, human relationships with humans there are 50 quotations, human relationships with God are 8, and the total of these quotations is 149 quotations. Whereas in Ivanna Van Dijk's novel the moral value of human relations with oneself is 26 quotations, human relationships with humans there are 49 quotations, human relationships with God there are 3 quotations, and the total of these quotations is 105 quotations. Conclusion, the comparison of moral values in the two novels is on the number of citations, while the equation lies in the form of quotations of moral values, which dominates the moral values of relationships with others. In addition, the form of expressing the moral values of the two novels is slightly different, namely the implied and explicit meaning.

Keywords: Comparison, Novel, Moral Value

\section{PENDAHULUAN}

Karya sastra adalah ungkapan pikiran, ide, gagasan yang ingin disampaikan pengarang yang dituangkan dalam sebuah tulisan. Kekhasan dalam karya sastra dapat dilihat dari berbagai sudut pandang baik dari isi maupun bentuknya. Penggambaran peristiwa yang terjadi pada masyarakat, lingkungan, dan pengalaman pribadi pengarang merupakan wujud dari kreatifitas dan imajinasi pengarang. Karya sastra terdiri dari puisi, prosa fiksi, dan drama. Drama salah satu karya sastra yang sangat menarik karena pada dasarnya drama merupakan seni pertunjukan berdialog dengan menggunakan bahasa-bahasa yang indah dan gerak tubuh atau aksi lakon (Susanto, 2016). Puisi merupakan karya sastra dengan memfokuskan padakata-kata sebagai objek yang dihasilkan oleh pengarang, penggunaan kata pada puisi bersifat padat dan memiliki unsur estetika.

Sedangkan prosa fiksi ialah suatu karya sastra yang disajikan dengan cara menceritakan atau naratif bisa berupa kehidupan nyata atau tidak nyata (khayalan). Prosa fiksi terbagi lagi atas cerita pendek, roman, dan novel. Novel adalah rangkaian cerita yang panjang dijabarkan dengan mengkaitkan cerita kehidupan melalui penampilan watak, sifat, dan pelaku dalam novel juga ada pesan yang ingin disampaikan oleh pengarang. Novel akan lebih menarik jika proses diciptakan dengan pemilihan ide yang tepat, selain itu novel harus didukung dengan unsur pembangun dalam novel agar lebih mengesankan bagi para pembaca. Unsur tersebut adalah unsur dari dalam seperti tema, tokoh/penokohan, alur, latar/setting, sudut pandang, gaya bahasa dan amanat. 
Selain itu novel juga tidak lepas dari unsur pembangun dari luar yang sangat mempengaruhi dan memberi dampak bagi setiap karya sastra. Unsur dari luar tersebut ialah unsur biografi, unsur sosial, dan unsur nilai. Nilai yang terdapat dalam novel merupakan pesan dan amanat yang disampaikan pengarang baik secara tersirat maupun secara langsung melalui cerita yang ditonjolkan melalui karakter dan sifat tokoh dalam cerita.

Hasil penelitian Nugroho dan Yasafiq (2018) menunjukan jika kedua novel tersebut memiliki perbedaan dalam segi penyapaian nilai sosial. Selanjutnya Hasana (2017) menjelaskan berdasarkan hasil penelitian jika terdapat 3 bentuk nilai moral kemasyarakatan dan satu nilai moral relegius. Namun dalam penelitian ini nilai yang disampaikan pengarang akan memberi kesan pada pembaca dan memberikan pembelajaran dalam kehidupan. Hal ini sangat unik karena pembaca diharapkan untuk dapat mengambil pembelajaran atas nilai- nilai yang telah disisipkan pengarang pada cerita. Sehingga peneliti tertarik untuk mengapresiasi nilai moral yang terdapat pada novel yang berjudul "Ananta Prahardi" dan "Ivana Van Dijk". Penelitian ini akan membandingkan nilai moral yang terdapat dalam kedua judul novel tersebut.

\section{METODE PENELITAN}

Penelitian ini menggunakan penelitian deskriptif kualitatif. Penelitian kualitatif digunakan untuk memperoleh gambaran mengenai nilai moral novel Ananta Prahadi dan Ivanna Van Dijk karya Risa Saraswati. Pada intinya penelitian kulitatif adalah penelitian yang menjabarkan secara objektif secara sebenarya pada objek penelitian.Penelitian menggunakan metode content analysys (analisis isi) yaitu berupa pendekatan yang nantinya akan menghasilkan suatu kesimpulan tentang gaya bahasa baku, kecenderungan isi buku, tata tulis, lay-out ilustrasi dan lainnya. Berdasarkan konsep hasil metode analisis menurut ahli di atas, maka dalam penelitian ini peneliti akan melakukan analisis pada bagian kecenderungan isi buku yang berupa nilai-nilai yang ada dalam novel Ananta Prahadi dan Ivanna Van Dijk karya Risa Saraswati terfokus pada nilai moral.

Ditinjau dari paradigmanya, penelitian ini termasuk ke dalam studi kepustakaan dan memiliki karakteristik sebagaimana dicirikan oleh rancangan kualitatif. Karakter tersebut adalah sebagai berikut: (1) novel dan dokumen cetak lainnya 
dipandang bersifat alamiah dikarenakan peneliti tidak melakukan rekayasa terhadap isi dari teks-teks novel; (2) novel yang berjudul Ananta Prahadi dan Ivanna Van Dijk karya Risa Saraswati dipandang sumber data langsung yang berupa dokumen dan peneliti sebagai instrumen kunci secara hermeneutis dapat memahami novel; (3) pembahasan dan pemaparan bersifat deskriptif; (4) lebih mementingkan proses daripada hasil; (5) analisis secara induktif; (6) makna nilai moral yang tersirat menjadi perhatian utama; (7) desain bersifat sementara; (8) pengambilan sampel secara purposife; dan (9) hasil penelitian kualitatif tidak dapat digeneralisasikan pada kasus yang lebih luas melainkan berlaku pada kasus yang diteliti saja.

Data dalam penelitian ini adalah nilai moral yang terdapat dalam novel Ananta Prahadi dan Ivanna Van Dijk karya Risa Saraswati. Sedangkan sumber data dalam penelitian ini adalah berupa kata-kata, frase kalimat tertulis yang dicermati oleh peneliti, dan benda-benda yang diamati sampai detailnya agar dapat ditangkap makna yang tersirat dalam dokumen. Dokumen yang dimaksud yaitu novel Ananta Prahadi karya Risa Saraswati yang diterbitkan oleh PT. Bukene Kreatif Cipta, Jakarta tahun 2018 dengan ketebalan berjumlah 246 halaman dan novel Ivanna Van Dijk karya Risa Saraswati yang diterbitkan oleh PT. Bukene Kreatif Cipta, Jakarta tahun 2018 dengan ketebalan berjumlah 211. Dan buku-buku yang berkaitan dengan sastra, nilai moral, dan pengajaran sastra lain merupakan penunjang utama dalam proses analisis.

Prosedur analisis data yang digunakan dalam penelitian ini adalah analisis deskriptif. Analisis deskriptif digunakan untuk menganalisis data yang ada pada objek penelitian. Tujuan metode analisis data deskriptif yaitu untuk mendeskripsikan dan menganalisis kondisi yang tekandung dalam novel Ananta Prahadi dan Ivanna Van Dijk karya Risa Saras Wati, di dalamnya terdapat upaya mengklasifikasikan data, mendeskripsikan, dan meganalisis kondisi yang terkandung dalam novel tersebut. Dalam penelitian ini, teknik analisis deskriptif digunakan untuk menganalisis perbandingan nilai moral novel Ananta Prahadi dan Ivanna Van Dijk karya Risa Saras Wati, yaitu sebagai berikut: 


\section{HASIL PENELITIAN}

\section{Analisis Nilai Moral Novel Ananta Prahadi karya Risa Saraswati}

Berdasarkan hasil analisis diketahui terdapat nilai moral pada novel Ananta Prahadi karya Risa Saraswati. Hal ini dapat dilihat dari salah satu bab, sebagai berikut: Pada BAB 1 halaman 8 menggambarkan bagaimana hubungan antara Ananta dan Tania yang baru pertama kali bertemu, berikut narasinya:

(001/2) ... “Teh, jangan tidur atuh Teh, ayo kenalan Teh!”...

Narasi di atas menunjukan di mana sebagai murid baru, tokoh Ananta mengajak berkenalan dan bersikap ramah terhadap teman sebangkunya, Tania.

Selanjutnya pada BAB 2, halaman 12 menunjukan bagaimana hubungan Tania dengan Ananta, berikut kutipannya:

(003/2)...Tapi Ananta selalu memotivasiku untuk tetap percaya diri terhadap hasil karya...

Kutipan di atas menggambarkan sebagai seorang sahabat dan rekan kerja Ananta memberikan hal positif bagi Tania salah satunya memberikan memotivasi.

Pada BAB 16 halaman 139 terdapat hubungn manusia dengan manusia, berikut kutipannya:

(038/2)...Sempat terlintas kecemburuanku saat melihat kedekatan mereka, tapi aku sadar...mungkin Tiara memang membutuhkan teman seperti Sukma di rumah ini, bukan seperti aku yang selalu tak acuh padanya...

Pada narasi di atas menunjukan bagaimana hubungan yang kurang baik antara Tania dan adiknya Dania karena sikap Tania yang egois dan acuh tak acuh pada keluarganya. Akhirnya Dania lebih akrab dan dekat dengan Sukma daripada kakaknya sendiri. Hal terebut membuat Tania cemburu pada Sukma karena bisa dekat dengan adiknya.

\section{Analisis Nilai Moral Novel Ivanna Van DijkKarya Risa Saraswati}

Sedangkan nilai moral pada novel Ivana Van Dijk dapat dibaca pada beberapa BAB diantaranya:

Pada BAB Ihalaman 10 terdapat narasi yang menunjukan hubungan manusia dengan diri sendiri dimana pengarang menunjukan rasa takut. Berikut kutipannya:

(001/1)...Dan tiba-tiba, lampu koridor mati, membuatku kaget dan sangat ketakutan.... 
Kutipan di atas menggambarkan suasana ketakutan dikarenakan tiba-tiba lampu koridor mati dan membuatnya kaget.

Pada BAB III ini menceritakan bagaimana keluarga Van Dijk berbahagia atas perpindahannya ke Hindia Belanda dan menggambarkan keharmonisan dan penuh kasih sayang keluarga kecil Van Dijk. Berikut narasi yang menggambarkan hubungan manusia dengan manusia, halaman 19:

(002/2)...Yang istimewa dari Peeter Van Dijk adalah rasa kekeluargaannya yang sangat tinggi. Di sela kesibukan pekerjaannya yang padat, diselalu mencurahkan perhatian dan kasih sayang terhadap keluarga kecilnya...

Sebagai kepala keluarga Peeter Van Dijk harus dapat menciptakan suasana keluarga yang penuh dengan kasih sayang dan harmonis. Apalagi Peeter Van Dijk adalah seorang abdi negara Netherland yang memiliki waktu terbatas sehingga ia berusaha semaksimal mungkin agar hubungan terhadap keluarganya terjalin dengan baik penuh dengan kasih sayang, perhatian, dan menumbuhkan kerhamonisan didalam keluarga kecilnya.

Pada BAB 18 halaman 138 menggambarkan bagaimana hubungan anatara Ivanna dan Dimas sebagai kakak adik, berikut narasinya:

(035/2)...Ivanna Van Dijk mendengarkan cerita adiknya dan berpesan agar Dimas tetap sabar dan terus berjuang, karena tidak ada yang mustahil di dunia ini. Ivanna sadar betul, itu hanya basa-basi, sama sekali belum terbukti kebenarannya...

Narasi tersebut menunjukan bagaiamana hubungan Ivanna yang sangat menyayangi adiknya dengan berpesan agar Dimas tetap sabar dan berjuang. Ivanna juga memotivasi adiknya dengan kata-kata tidak ada yang mustahil di dunia ini walaupun sebenarnya Ivanna hanya sekedar basa-basi tetapi itu merupakan wujud dari kasih sayang dan peduli kakak terhadap adiknya.

Pada BAB 19 halaman 145 menggambarkan bagaimana perasaan Ivanna berikut narasinya:

(013/1)...Di tengah kebahagiaan melihat sang adik yang sangat bersemangat, hati Ivanna menggeliat resah...

Narasi tersebut menunjukan bagaiamana perasaan dan suasana hati Ivanna yang resah dan cemas. Walaupun sebenarnya ia bahagia melihat adiknya bersemangat. Kekhawatiran Ivanna ialah bagaimana ketika besok keluarga Brouwer datang. 
Pada BAB 20 halaman 154 menggambarkan bagaimana hubungan orangtua dan anaknya, berikut narasinya:

(040/2)...Suzie Van Dijk mulai memahami kesalahan dirinya dan Peteer pada masa lalu. Seharusnya, mereka tak usah memberi nama Dimas pada anak bungsu mereka. Peristiwa kemarin membuatnya sadar bahwa itu kesalahan fatal...

Narasi tersebut menunjukan bagaimana Peteer dan Suzie menyesal sebagai orang tua mereka tak berpikr panjang terhadap putranya yang mereka beri nama Dimas yang merupakan kesalahan yang sangat fatal bagi anak bungsunya itu.

Pada BAB 26 halaman 206 terdapat hubungan manusia dengan diri sendiri, berikut kutipannya:

(026/1)..."Aku tetap tak bahagia. Dendamku masih membara, amarahku masih berkobar. Tak ada yang bisa kulakukan selain menyalahkan diriku yang memang salah... "...

Kutipan tersebut menunjukan bahwa perasaan Ivanna yang penuh dengan keterombang-ambingan bagaimana tidak Ivanna tetap tidak bahagia walaupun dendamnya sudah terbalaskan. Dan tetap saja dalam hatinya dendm itu masih ada walaupun sudah ia balaskan. Dalam keterombang-ambingnnya membalas dendam ia menyalahkan dirinya bahwa perbuatannya itu memang salah.

\section{PEMBAHASAN}

\section{Perbandingan Nilai Moral Novel Ananta Prahadi dan Ivanna Van DijkKarya Risa}

\section{Saraswati}

Perbandingan nilai moral kedua novel tersebut dari aspek nilai moral terdapat perbedaan. Pada novel Ananta Prahadi karya Risa Saraswati nilai moral hubungan manusia dengan diri sendiri terdapat 19 kutipan, hubungan manusia dengan manusia terdapat 50 kutipan, hubungan manusia dengan Tuhan terdapat 8, dan keseluruhan dari kutipan tersebut adalah 149 kutipan. Sedangkan pada novel Ivanna Van Dijk nilai moral hubungan manusia dengan diri sendiri terdapat 26 kutipan, hubungan manusia dengan manusia terdapat 49 kutipan, hubungan manusia dengan Tuhan terdapat 3 kutipan, dan keseluruhan dari kutipan tersebut adalah 105 kutipan.

Perbedaan pada nilai moral novel Ananta Prahadi dan Ivanna Van Dijk karya Risa Saraswati adalah pada novel Ananta Prahadi menunjukan hubungan manusia 
dengan manusia dimana wujud kasih sayang persahabatan antara Ananta dan Tania. Hal ini sesuai dengan pendapat Nurgiyantoro, (2010) jika nilai moral hubungan manusia dengan diri sendiri, hubungan manusia dengan manusia lain dalam lingkup sosial termasuk hubungannya dengan lingkungan alam, dan hubungan manusia dengan tuhannya. Sedangkan dalam novel Ivanna Van Dijk adalah hubungan manusia dengan manusia, bagaimana wujud kasih sayang dan kecintaan Ivanna pada keluarganya dan membalas demdam terhadap apa yang telah diperlakukan kepada keluarga Van Dijk.

Kemudian mengenai hubungan manusia dengn Tuhan pada novel Ananta Prahadi wujud hubungan dengan Tuhan adalah dengan bersyukur, beribadah, dan menjahui larangan-Nya. Sedangkan pada novel Ivanna Van Dijk wujud hubungan dengan Tuhan adalah hanya beribadah. Selanjutnya perbedaan pada nilai moral hubungan manusia dengan diri sendiri pada novel Ananta Prahadi adalah mengenai perasaan ketakutan Tania yang akan terjadi pada sahabatnya Ananta, sedangkan pada novel Ivanna Van Dijk mengenai harga diri yang dialami oleh Ivanna.

Perbedaan juga terjadi pada isi dan aliran novel tersebut pada novel Ananta Prahadi bergenre persahabatan atau romantis sedangkan Ivanna Van Dijk adalah penghiatan dan dendam Ivanna serta bergenre horor. Persamaan pada novel tersebut adalah pada pengarang yaitu Risa Saraswati sebagai pengarang novel Ananta Prahadi dan novel Ivanna Van Dijk.

\section{SIMPULAN}

Terdapat perbandingan antara nilai moral dalam novel Ivanna Van Dijk karya Risa Saraswati dengan nilai moral novel Ananta Prahadi karya Risa Saraswati. Pada novel Ivana Van Dijk karya Risa Saraswati bentuk penyapaian nilai moral lebih dominan pada hubungan dengan sesama. Pengambaran nilai moral baik tersurat maupun tersirat lebih mudah dipahami pembaca secara umum. Sedangkan novel Ananta Prahadi karya Risa Saraswati memiliki dominasi pada nilai moral hubungan dengan manusia. Pengambaran nilai moral lebih kompleks, sehingga menarik bagi pembaca secara umum. Berdasarkan penjelasan tersebut baik novel novel Ivanna Van Dijk karya Risa Saraswati maupun novel Ananta Prahadi karya Risa Saraswati, memiliki ciri khas tersendiri dalam menyampaikan nilai-nilai di dalamya, akan tetapi memiliki karateristik yang sama karena ditulis pengarang yang sama. 


\section{DAFTAR PUSTAKA}

Hasanah, U. (2017). Nilai Moral dalam Saq Al-Bambu karya Sa'ud Al-San'Usi. Jurnal: Adabiyyat (Jurnal Bahasa dan Sastra), 1(1), 112-138

Nugroho. A \& Yasafiq. (2018). Perbandingan Novel Ivanna Van Dijk Karya Risa Saraswati dan novel Ananta Prahadi karya Risa Saraswati elalui Pendekatan Sosiologi. Jurnal Silampari, 1(1), 1-10

Nurgiyantoro, B. (2010). Teori Pengkajian Fiksi. Yogyakarta: PT Buku Seru

Saraswati, R. (2018). Ananta Prahadi (Cetakan Pertama) .Jakarta : PT Bukune Kreatif Cipta

Susanto. (2016). Pengantar Kajian Sastra. Yogyakarta:PT Buku Seru 